\title{
Experimental Research on the Connection of Light Composite Wall Panels and the Steel Frame
}

\author{
Jiuyang $\mathrm{Li}^{1, \mathrm{a}}$, Lihua Liu ${ }^{1, \mathrm{~b}}$ and Bingbing Wang ${ }^{1, \mathrm{c}}$ \\ ${ }^{1}$ School of Civil Engineering, Changchun Institute of Technology, Changchun,China \\ a429838648@qq.com, '854363875@qq.com, 504921917@qq.com
}

\begin{abstract}
Keywords: composite wall panel, steel frame, connection
Abstract. In this paper, the bearing forces and anti-seismic properties of the wall panels and connection through the experimental research on the two connecting modes of the two composite wall panels with the steel frame are obtained, which provides the theoretical reference for the development and popularization of the steel frame envelope system.
\end{abstract}

\section{Introduction}

With the development and application of the green building, the steel framework has gradually become the direction of application of the civil building framework system. The research on the external steel frame envelope system has been developed in recent years. On the one hand, the research and production of some retaining walls such as aerated concrete wall panels, steel wire net frame cement sandwich plates, metal composite panels, plant fiber cement plates and GRC plates, etc. have become more and more mature; on the other hand, there is less research on the connection of the retaining walls with the steel frame principal structures. Basically, the traditional welding or bolt connection is still taken, the construction speed is high, but the flexibility of connection is poor and it is seriously destroyed in the occurrence of an earthquake. In this paper, based on the research on the

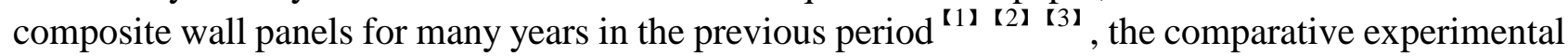
research is carried out for the external semi-hanging of the composite wall panel and the steel frame principal part, the bearing force and anti-seismic property of connection of the composite wall panel with the steel frame is obtained, which provides the reference for the engineering application of the composite wall panels.

\section{Test wall panels and test operating conditions}

In the test, there are two types of composite wall panels and 2 connection modes.

The operating conditions of the wall panels are as follows: the first type of wall panel (Y type) has been produced and used in a local enterprise, its thickness is $300 \mathrm{~mm}$, the thickness of the volcanic ash light concrete plate on the internal and external sides is 50mm, with the built-in $\phi 3 @ 50 \mathrm{HRB} 400$ steel wire gauze and the heat preservation layer of $200 \mathrm{~mm}$ thick, the molded EPS is taken, the three layers of materials are connected with the $\phi 8 \mathrm{HRB} 400$ steel bar truss and the truss is laid according to the structural requirement; the second type of composite wall panel ( $\mathrm{X}$ type) is the new sandwich composite wall panel modified by the Project Group, its thickness is $250 \mathrm{~mm}$, the thickness of the volcanic ash light concrete plates on the internal and external sides is $50 \mathrm{~mm}$, with the built-in $\phi 5 @ 200$ CRB500 steel wire gauze and the 150mm-thick heat preservation layer of XPS and the three layers of materials are connected with the $\phi 5$ CRB500 steel bar truss.

The connection mode of the test wall panel and the principal structure is the external semi-hanging, that is, the external-layer concrete is out of the section of the frame column (longitudinal frame beam) and the hot bridge phenomenon can be avoided in the engineering application. The form of the connecting node of the $\mathrm{Y}$ type of wall panel is called GZ1 and that of the X type of wall panel is called GZ2. 
See Figure 1 for the connecting mode of GZ1, with the detailed structure as follows: in the processing of the wall panel, at the connecting node of the wall panel is embedded a U-bar, $10 \mathrm{~cm}$ long, the lower flange of the U-bar is reserved with the bolt hole $(12+1.5 \mathrm{~mm})$; the upper flange in the connecting position of the frame beam is reserved with the bolt hole $(12+1.5 \mathrm{~mm})$, and in order to reduce the impact of the flange opening impairing the steel frame beam, a steel plate can be welded and the same bolt hole is opened on the steel plate; after the wall panel is hoisted in place, the M12 bolts penetrate the flange, welded steel plate and the bolt hole of the lower flange of the steel frame from the lower side of the lower flange of the steel beam one by one, screw the bolt caps and finally use the foam concrete or PU to stuff and block the steel frame.

See Figure 2 for the connecting mode of GZ2: in the designed connecting position is embedded an I-shaped embedment (consisting of 2 steel plates and 2 sleeves) and the internal and external layers of steel plates of the I-shaped embedment are $150 \times 120 \times 6 \mathrm{~mm}$ in the internal and external layers of concrete of the wall panel; the internal steel plate is on the same level with the internal surface of the wall panel; the sleeve, half of which is close to the external side is solid and the other half close to the internal side is the M14 internal thread sleeve, on the same level with the internal surface of the wall panel (the steel sleeve should be blocked to prevent the concrete from blocking in the making); the upper surface in the connecting position of the frame beam is welded with the connecting steel angle L $90 \times 10,15 \mathrm{~cm}$ long, on the vertical bracing is opened with the bolt hole $(14+1.5 \mathrm{~mm})$; after the wall panel is hoisted in place, use the bolt to connect and tighten the vertical bracing of the steel angle and the sleeve in the wall panel embedment.

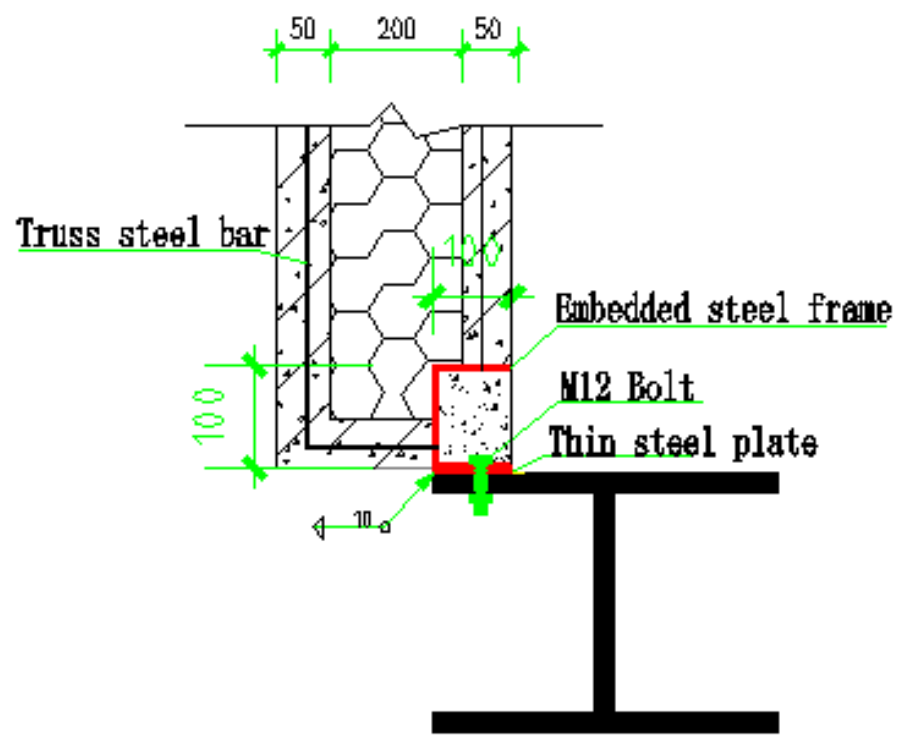

Figure 1 Connecting Node of GZ1 


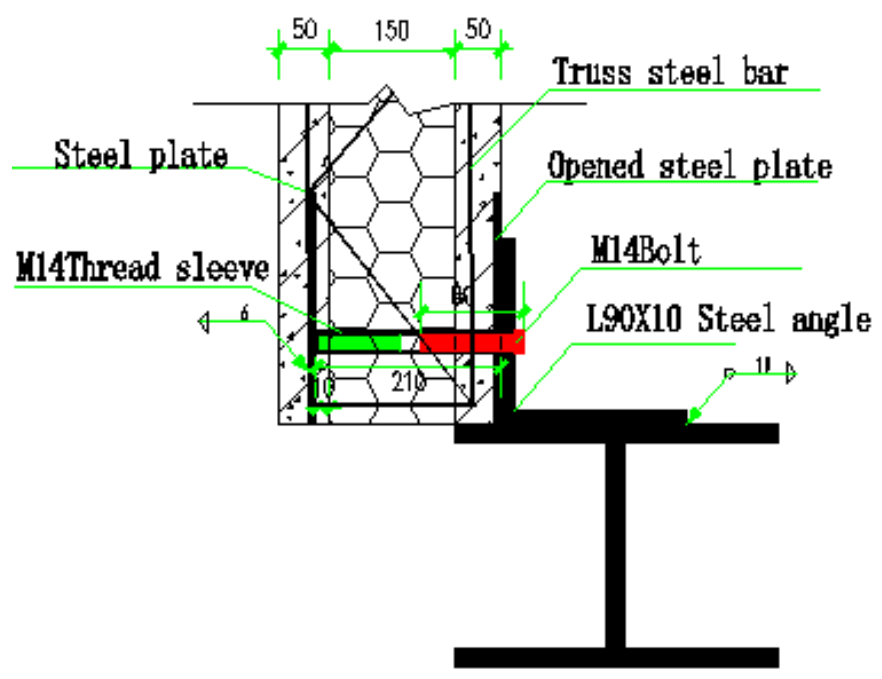

Figure 2 Connecting Node of GZ2

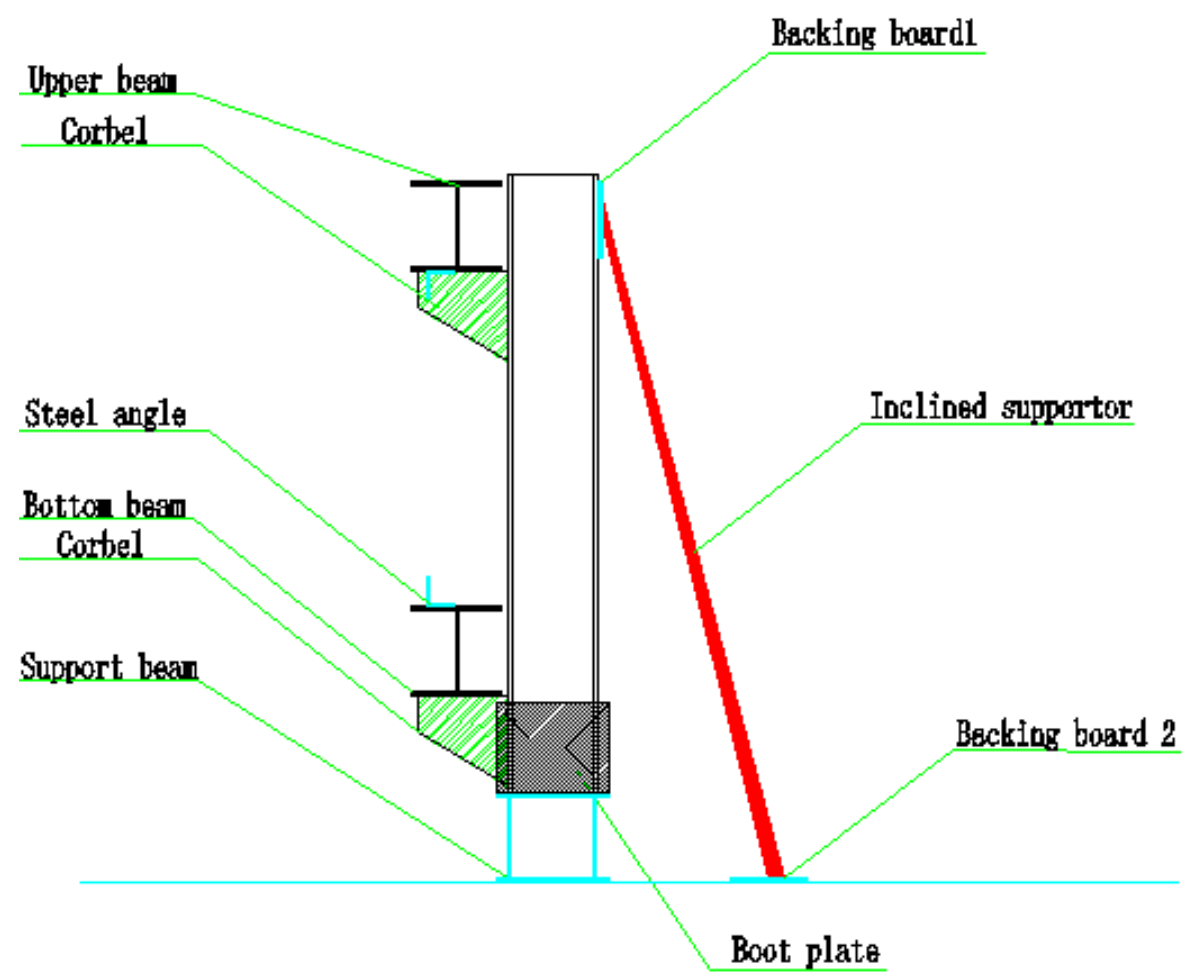

Figure 3 Side View of the Loading Frame 


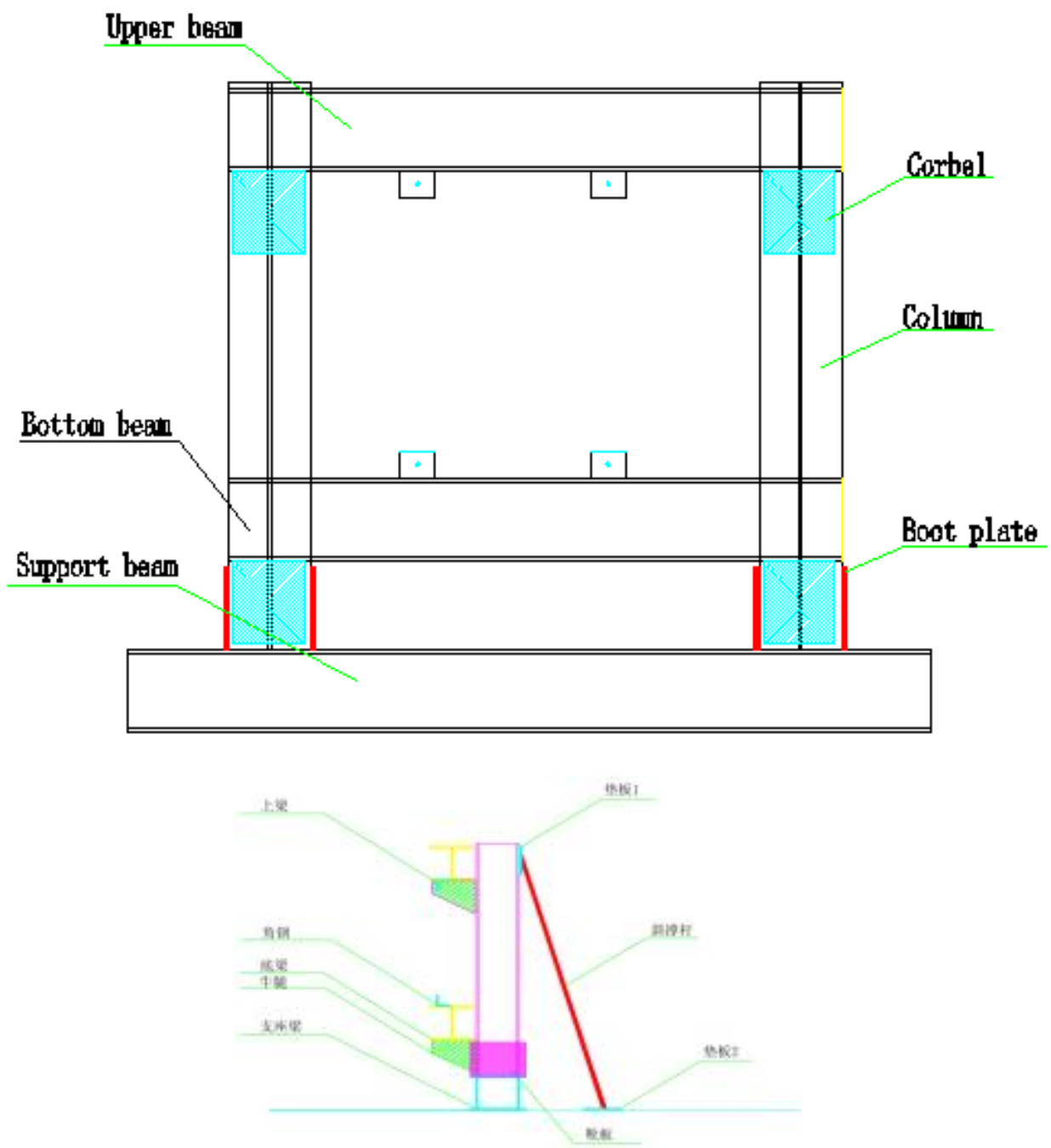

Figure 4 Front View of the Loading Structure

Truss steel bar,Embedded steel frame,Bolt,Thin steel plate,Steel plate,Thread sleeve,Opened steel plate,teel angle,Upper beam,Backing board,Bottom beam,Corbel,Support beam,Boot plate,Steel column

It is considered that the test pieces of the project should be connected and loaded to the same frame as soon as possible, the design of the loading frame should meet the connecting and bearing forces of all the test pieces, the material used for the loading frame is the Q345 steel, including the support beam, 2 frame columns, 2 beams (upper beam and bottom beam), corbel and diagonal bracing. The steel beam and steel column are the hot rolled $\mathrm{H}$-shaped steel, the model of the section of the frame beam is HW $350 \times 350 \times 12 \times 19$, the model of the section of the fame column is HW $350 \times 350 \times 12 \times 19$, the model of the section of the support beam is HW350 $\times 450 \times 12 \times 19$ and the steel diagonal bracing is the U-bar [ $250 \times 82 \times 11 \times 12]$. The structure of the loading structure is shown in Figure 3 and Figure 4 and the wall panel is installed 2 steel beams and wall columns.

\section{Test loading}

The pseudo static low cyclic loading is taken for the test, the load is directly imposed upon the composite wall panel so as to simulate the seismic force acting on the wall panel and the force bearing mechanism and destruction form of the wall panel and connecting node on the effect of the seismic force are researched. At present, there are mainly three methods for the pseudo static test loading system often taken at home and abroad: (1) force control loading method (2) displacement control 
loading method (3) force and displacement control mixed loading method ${ }^{[4]}$. The structure bears the gradually increasing cyclic loading. When the load obviously decreases (to less than $85 \%$ of the peak load) or one of the following phenomena occurs, it is thought that the test piece loses the bearing force and reaches the destruction state. (1). The bolt is cut. (2) The concrete in the local area of the wall panel is crushed. (3) Serious cracks occur on the surface of the wall panel and penetrate the wall panel. ${ }^{[5]}$ 。

In order to assure the accuracy of the test data and the reliability of the result analysis, before the formal loading of the test, the pre-loading of the test piece is first made to test the working properties of the machine and the loading system. First pre-load $2 \mathrm{KN}$ and to $5 \mathrm{KN}$ and then to 0 and repeat it twice. In the pre-loading process, observe whether the strains and displacements of all the test nodes are in the linear increase; when unloading is 0 , whether the readings of all the test nodes return to the initial readings.

In the formal loading, the force control method is first taken, the horizontal cyclic centralized force is imposed upon the middle position of the test piece via the hydraulic servo actuator, take the horizontal pushing force of the actuator as the positive direction and the pulling force is the negative direction, first impose the pushing force and then the pulling force. The initial value is $0 K N$, take $\pm 5 K N$ as the loading step to gradually increase the load, each level of load is kept for $2 \mathrm{~min}$, and then impose the next level of load, and after the member or connecting yield, the displacement control method is taken and the 1 time yielding displacement and twice yielding displacement, etc. are applied, respectively until the member is destroyed.

\section{Test phenomenon and analysis}

In the loading of the Y1 wall panel, before the cyclic load is less than $20 \mathrm{KN}$, on the surface of the wall panel is observed no crack and the loading path nearly completely coincides with the unloading path and the wall panel is in the elastic phase; when it is loaded to $30 \mathrm{KN}$, a few fine inclined cracks occur around the embedment in the lower left corner of the wall panel and on the back of the wall panel and the test piece obviously displaces; when it is loaded to $40 \mathrm{Kn}$, the bolt of the connecting node of the wall panel and the connecting steel plate are dislocated to produce the clear friction noise; when it is loaded to $50 \mathrm{KN}$, the crispy "bang bang" sounds from the test piece and (or) the connecting node, the deformation of the connecting node is increased, the loading frame slides and the friction displacement occurs to the support beam and the anti-pulling bolt; when it is continued to $70 \mathrm{KN}$, the inclined cracks around the embedment on the lower left corner and lower right corner of the wall panel are obviously widened and deepened and the new cracks occur; when it is loaded to $80 \mathrm{KN}$, the inclined cracks round the embedment on the lower left corner and lower right corner of the wall panel penetrate the wall, the bolt of the connecting node yields and the shearing deformation visible to the bared eyes occurs; when it is loaded to $90 \mathrm{KN}$, the bolt of the connecting node in the lower part of the wall panel is cut, and at this time, the wall panel loses the bearing capacity, and the loading is stopped to obtain its load-displacement hysteresis curve shown in Figure 5.

In the loading of the $\mathrm{X} 1$ wall panel, before the cyclic load is less than $70 \mathrm{KN}$, the test piece and nodes basically tend to be the same with those of the Y1 test piece, and later, the X1 wall panel and GZ2 connecting node tend to the high ductility and bearing force; when it is loaded to $80 \mathrm{KN}$, the inclined cracks in the upper part of the embedment in the lower left corner and lower right corner of the wall panel are continuously widened and deepened, that is, getting through and the new cracks occur and the accumulated injury has become more and more obvious with the repeated loading; when it is loaded to $90 \mathrm{KN}$, a lot of cracks occur around the embedment of the four corners of the wall panel, and the inclined cracks of the embedment in the lower left corner and lower right corner and the cracks in the middle line on the back penetrate the wall; when the $120 \mathrm{KN}$ cyclic loading is applied, the concrete of the embedment seriously peels off, the bolt of the connecting node of the wall panel is cut, the structure loses the bearing capacity and the loading is stopped. 
In the test, the actuator loading system records the horizontal load-displacement (p- $\Delta$ ) relation hysteresis curve of the model and the $\mathrm{p}-\Delta$ hysteresis curve of each model is shown in the figure 6 .

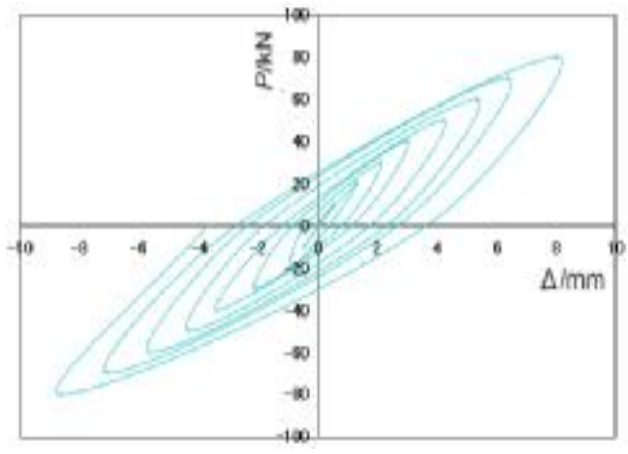

Figure $5(\mathrm{p}-\Delta)$ Hysteresis Curve of GZ1
Figure $6(p-\Delta)$ Hysteresis Curve of GZ2

\section{Test conclusion}

According to the test data and the load-displacement $\mathrm{p}-\Delta$ relation hysteresis curve drawn, the following conclusion can be drawn:

(1) With the gradual imposition of the load, the loading and unloading law of the test piece and connecting node is obvious. The slope of the line is gradually reduced, the residual deformation is gradually accumulatively increased, indicating that the rigidity of the structural systems is gradually degraded on the effect of the reciprocal load and the envelope system shows the good ductility. The

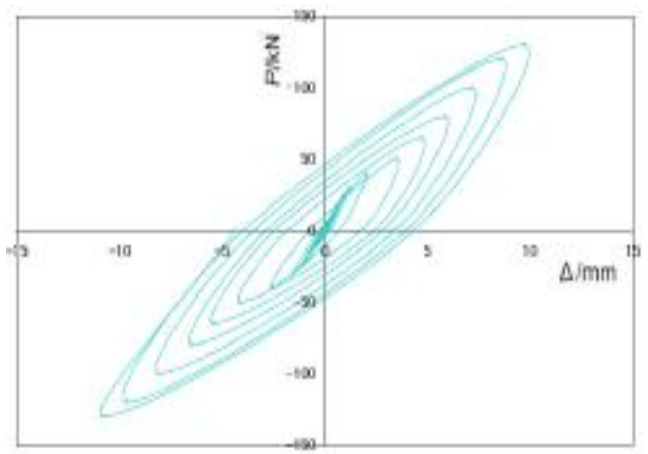

reasons for degradation of the rigidity: one the one hand, the concrete around the embedment of the wall panel is pushed and pulled to be cracked, the rigidity of the wall panel is reduced; on the other one, the node connected with the frame slowly enters the plastic phase from the elastic phase and the rigidity as a whole is continuously reduced.

(2) With the gradual increasing of the reciprocal load, the test piece and the connecting node go through the elastic phase, yielding phase and destruction phase, the area of the circle of the load-displacement p- $\Delta$ relation hysteresis curve is gradually increased with the increasing of the load, indicating that the consumptive capacity of the envelope is strong and it can absorb more seismic energy in the occurrence of an earthquake, with the good anti-seismic property.

(3) In the case of no big difference between the costs, the bearing force of the X1, GZ2 envelope system is $120 \mathrm{kN}$ more than the bearing force of $90 \mathrm{kN}$ of the Y1, GZ1 envelope system; in addition, the concave slot should be reserved in the processing and making of the wall panel in the connecting mode of GZ1, it will be damaged in the transport after the wall panel is impaired and the space is small in the construction and installation, the construction and installation is convenient in the connecting mode of GZ2, but the post treatment of the exposed part should be carried out. With the experimental research of the project, the theoretical basis is provided for the production and construction enterprises, which can choose the suitable wall panels and connecting modes according to the demands. 


\section{Acknowledgements}

This work was financially supported by the Jilin Science and Technology Development Planned Topics[20140203014SF] and Jilin Education Development Planned Topics[2015296]

\section{References}

[1] ZHANG Li, etc. Finite Element Analysis on the Deformation of Energy-saving Wire-mesh Frame

[2] Wallboard [J]. Journal of Changchun Institute of Technology 2012 (4): 1

[3] LIU Lihua, etc. Design of Energy-saving Wire-mesh Frame Wallboard in Extreme Cold Area under Horizontal

Load [J]. Journal of Changchun Institute of Technology 2011(1): 1-3

[4] Jiuyang Li. Analysis of deformation of composite wall cladding panel. ICECE2011 5193-5196

[5] Jiuyang Li. Finite element analysis of displacement of composite wall cladding under wind load, TCE2011

p2261-2264, 2011.4 